\title{
Angiographic Results of Radial Artery Graft Patency in Patients Undergoing Coronary Artery Bypass Grafting Surgery
}

\author{
Yaron Ishay*1, Lior Raichel ${ }^{1}$, Jean Marc weinstein ${ }^{2}$, Menachem Matsa ${ }^{1}$, Oren Lev-Ran ${ }^{1}$, Zvi \\ Perry $^{3}$, Carlos Cafri ${ }^{2}$ and Gideon Sahar ${ }^{1}$ \\ ${ }^{1}$ The Department of Cardiothoracic Surgery, Soroka University Medical Center, Faculty of Health Sciences, Ben Gurion University \\ of the Negev, Beer Sheva, Israel
}

${ }^{2}$ Cardiology Department, Soroka University Medical Center, Faculty of Health Sciences, Ben Gurion University of the Negev, Beer Sheva, Israel

${ }^{3}$ Department of Surgery A, Soroka University Medical Center, Faculty of Health Sciences, Ben-Gurion University of the Negev, Beer-Sheva, Israel

*Corresponding author: Yaron Ishay, The Department of Cardiothoracic Surgery, Soroka University Medical Center, Faculty of

Health Sciences, Ben Gurion University of the Negev, Beer Sheva, Israel

\section{ARTICLE INFO}

Received: 蔧 May 07, 2021

Published: 慧 May 21, 2021

Citation: Yaron Ishay, Lior Raichel, Jean Marc weinstein, Menachem Matsa, Oren Lev-Ran, et al., Angiographic Results of Radial Artery Graft Patency in Patients Undergoing Coronary Artery Bypass Grafting Surgery. Biomed J Sci \& Tech Res 36(1)2021. BJSTR. MS.ID.005786.

Abbreviations: CABG: Coronary Artery Bypass Grafting; RA: Radial Artery; LCX: Left Circumflex; RCA: Right Coronary Artery

\section{ABSTRACT}

Background: Although Radial artery (RA) grafts exhibit a significantly better patency rate in midterm to long term follow up compare to saphenous vein grafts, recent data suggest that the RA is used in less than $6 \%$ of all coronary artery bypass grafting (CABG) procedure.

Methods: Between 2007 and 2017, 241 consecutive Radial graft angiograms for postoperative cardiac symptoms were evaluated by two independent observers. Angiographic outcomes were divided into groups as (1) patent $(<70 \%$ stenosis), (2) severe disease ( $\geq 70 \%$ stenosis) or (3) total occlusion. Patency was examined by coronary target territory (right versus left), grafts configuration free graft versus composite graft and number of distal sequential anastomosis.

Results: A total of 2870 patients had a RA graft as part of CABG procedure. 380 distal radial anastomosis were examined; a range of 1-102 months post operatively. $46.5 \%$ were grafted the right coronary system, $53.5 \%$ to non-LAD left coronary system. $78.5 \%$ as free graft and $21.5 \%$ as a composite graft. $78 \%$ had at most, two sequential anastomoses. No correlation was found between patient's comorbidities, coronaries territories (right versus left) and grafts failure. Significant better patency rates were found for free grafts compare to composite grafts $(\mathrm{p}=0.013)$ and for less than 2 sequential anastomoses compare to $3(\mathrm{p}<0.01)$.

Conclusions: Clinical and angiographic patency rate of RA grafting non-LAD highgrade coronary artery stenosis are excellent as a free graft provided that no more than two sequential anastomosis are constructed.

\section{Background}

The earliest experience with use of the radial artery as a conduit for Coronary Artery Bypass Grafting (CABG) was in the early 1970's [1], with disappointing results of $35 \%$ graft failure due to spasm [2]. With better understanding of the morphology and physiology of the radial artery in the 1990s, the radial artery was reintroduced as an additional conduit in CABG [3]. Reflecting improved long-term patency rates and clinical outcomes, recent interest has focused on the increased use of arterial conduits in CABG. Although Radial Artery (RA) grafts exhibit a significantly better patency rate in 
mid- to long term follow up compared to saphenous vein grafts [4], recent data suggest that the RA is used in less than $6 \%$ of all CABG procedures [5]. Previous studies concentrated on target lesion severity as a predictor for graft failure. According to the most recent European guidelines [6], the use of radial artery is recommended as class IB for high-grade coronary artery stenosis $(>70 \%$, and even better for $>90 \%$ ) over the saphenous vein. The objective of this observational study was to review our experience over the past 10 years, particularly to evaluate the patency of the radial graft according to the target territory (left versus right coronary system), as a free graft (proximal anastomosis to the aorta) or composite graft ("T"-graft from the internal mammary artery) and according to the number of distal sequential anastomoses.

\section{Patients and Methods}

Between 2007 and 2017, 2370 consecutive patients underwent isolated CABG using cardiopulmonary bypass with the RA as a concomitant graft to non-LAD territory. 241 patients underwent angiograms for postoperative cardiac symptoms. Patients' preoperative demographic characteristics are depicted in Table 1.

Table 1: Patient demographics (preoperative).

\begin{tabular}{|c|c|c|}
\hline \multicolumn{2}{|c|}{$\mathbf{N = 2 4 1}$ patients } \\
\hline \multirow{2}{*}{ Age-yr } & & $64 \pm 0.39$ \\
\hline Male sex-(\%) & & $181(75 \%)$ \\
\hline \multirow{4}{*}{\begin{tabular}{c} 
Comorbidities (\%) \\
\cline { 2 - 3 }
\end{tabular}} & Dypertension & $183(75 \%)$ \\
\cline { 2 - 3 } & Piabetes mellitus & $113(46 \%)$ \\
\cline { 2 - 3 } & Smoking & $25(10 \%)$ \\
\cline { 2 - 3 } & Obesity (>30) & $132(55 \%)$ \\
\hline \multirow{2}{*}{$\begin{array}{c}\text { Left Ventricular } \\
\text { function }\end{array}$} & Normal - mild LVD & $111(46 \%)$ \\
\cline { 2 - 3 } & Moderate to severe & $84(35 \%)$ \\
\hline
\end{tabular}

Note: $P V D=$ peripheral vascular disease, (obesity-write in $\mathrm{BMI}>30), \mathrm{LVD}=$ left ventricular dysfunction.

\section{Radial Artery Graft Procedure and Spasm Prophylaxis}

An Allen test was routinely performed before RA harvesting from the non-dominant forearm. The RA was harvested as pedicle graft using the Harmonic scalpel. After harvesting, all had intraluminal papaverine injection and were then soaked in heparinized arterial blood and papaverine solution for spasm prevention.

\section{Post-Operative Graft Angiography}

241 consecutive radial graft angiograms for postoperative cardiac symptoms were evaluated by two independent observers. Angiographic outcomes were divided into three groups as

1. Patent $(<70 \%$ stenosis $)$

2. Severe disease ( $\geq 70 \%$ stenosis) or

3. Totally occluded.

Patency was examined by coronary territory, target vessel stenosis severity, grafts configuration and number of distal anastomosis.

\section{Grafting Strategy}

The RA grafts were grafted to non-LAD territories: Left Circumflex (LCX) or Right Coronary Artery (RCA). As a free graft (proximal anastomosis directly to the aorta) or as a composite graft (proximal anastomosis to the left internal mammary artery), as a single graft (single distal anastomosis per radial) or sequential anastomoses (2-3 distal sequential anastomoses per radial).

\section{Results}

A total of 2370 patients had a radial artery graft as part of on-pump CABG procedure. All consecutive 241radial grafts angiograms were performed due to cardiac symptoms; a range of 1-102 months post operatively. These comprised 380 anastomoses, of which 177 were grafted to the distal part of the RCA (PDAposterior descending artery, PLB- posterolateral branch), and 203 to non-LAD left coronary system (diagonal, marginal 1, marginal 2, left PDA) (Figure 1). Of these, 78.5\% (189 anastomoses) were performed as a free graft (proximal anastomosis direct to the aorta) $21.5 \%$ (52 anastomoses) as a composite graft (proximal anastomosis to the internal mammary artery). The numbers of sequential anastomoses in ascending order from 1 to 3 were 54.7 $\%$ (132 patients), 34\% (82) and 11.3\% (27) respectively. For 380 distal RA anastomoses, overall angiography patency was $72.9 \%$ (277 of 380). The best patency rate (86\%) was for single free grafts, whereas the worst was for 3 sequential anastomoses in composite graft configuration, with a patency rate of $61 \%$ (Table 2). No correlation was found between patients' comorbidities and graft failure. $75 \%$ of the patients were males; the patency rate was significantly higher in males compared to females (Table 3 ).

Table 2: Overall radial artery distal anastomosis failure according to surgical configuration.

\begin{tabular}{|c|c|c|}
\hline Configuration & $\begin{array}{c}\text { Number of Distal Sequential } \\
\text { Anastomoses (Total Anastomoses) }\end{array}$ & \% failure \\
\hline \multirow{2}{*}{ Free grant } & 1 graft (130) & $13.95 \%$ \\
\cline { 2 - 3 } & 2 graft (120) & $26.3 \%$ \\
\hline \multirow{3}{*}{ "Y" graft } & 1 graft (3) & 0 \\
\cline { 2 - 3 } & 2 grafts (46) & $36 \%$ \\
\cline { 2 - 3 } & 3 grafts (81) & $39 \%$ \\
\hline Total & 380 & $27.1 \%$ \\
\hline
\end{tabular}

Table 3: Gender, risks factors and patency.

\begin{tabular}{|c|c|c|}
\hline \multicolumn{2}{|c|}{ (Number) } & P* value \\
\hline $\begin{array}{c}\text { Smokers } \\
(132)\end{array}$ & $\begin{array}{c}\text { Nonsmokers } \\
(109)\end{array}$ & 0.891 \\
\hline $\begin{array}{c}\text { Diabetes mellitus } \\
(113)\end{array}$ & $\begin{array}{c}\text { Nondiabetic } \\
(128)\end{array}$ & 0.464 \\
\hline $\begin{array}{c}\text { PVD } \\
(25)\end{array}$ & $\begin{array}{c}\text { No PVD } \\
(216)\end{array}$ & 0.489 \\
\hline $\begin{array}{c}\text { Females } \\
(60)\end{array}$ & $\begin{array}{c}\text { Males } \\
(181)\end{array}$ & 0.031 \\
\hline
\end{tabular}




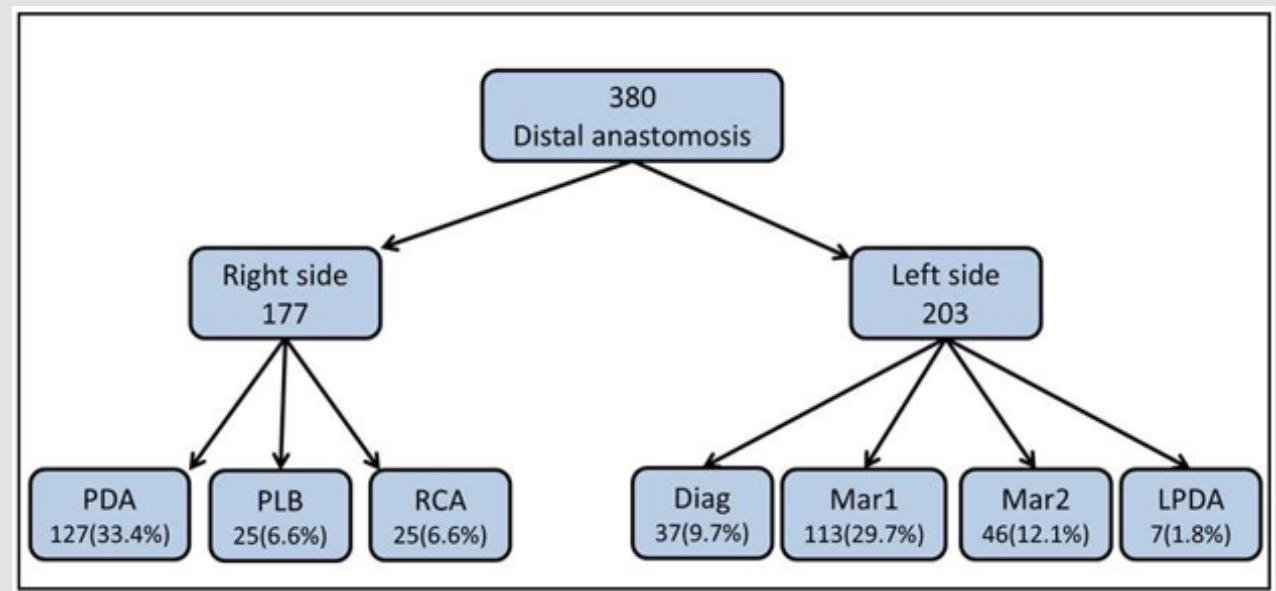

Figure 1: Non-LAD left vs right sided anastomosis.

There was no significant difference between non-LAD left side anastomoses versus right side graft patency. Patency rate was significantly inferior for composite grafts compared to free grafts and for more than 2 sequential anastomoses. There was no significant statistical difference between 1 versus 2 sequential free graft anastomoses (Table 4). Based on clinical outcomes, 10.17\% patients out of the 2370 had symptoms that required invasive graft stratification, demonstrating a graft failure rate of $27.1 \%$ This represents excellent clinical outcomes in about $90 \%$ of the whole cohort of patients.

Table 4: Surgical configuration and patency.

\begin{tabular}{|c|c|}
\hline Variable & P value \\
\hline Non LAD left side Vs Right & NS \\
\hline Free grafts Vs composite grafts & $\mathrm{P}=0.013$ \\
\hline Number of distal sequential anastomoses 2 Vs $>2$ & $\mathrm{P}<0.01$ \\
\hline Free graft 1 Vs 2 & NS \\
\hline
\end{tabular}

\section{Conclusion}

Clinical and angiographic outcomes for radial artery grafting to non-LAD high-grade coronary artery stenoses are excellent, better

\section{ISSN: 2574-1241}

DOI: 10.26717/BJSTR.2021.36.005786

Yaron Ishay. Biomed J Sci \& Tech Res

This work is licensed under Creative Commons Attribution 4.0 License

Submission Link: https://biomedres.us/submit-manuscript.php for males as a free graft, provided that no more than two sequential anastomoses are constructed.

\section{References}

1. Carpentier A, Guermonprez JL, Deloche A, Frechette C, Dubost C (1973) The aorta-to-coronary radial artery bypass graft: a technique avoiding pathological changes in grafts. Ann Thorac Surg 16: 111-121.

2. Geha AS, Krone RJ, McCormick JR, Baue AE (1975) Selection of coronary bypass: anatomic, physiological, and angiographic considerations of vein and mammary artery grafts. J Thorac Cardiovasc Surg 70(3): 414-431.

3. Acar C, Jebara VA, Portoghese M, Beyssen B, Pagny JY, et al. (1992) Revival of the radial artery for coronary artery bypass grafting. Ann Thorac Surg 54(4): 652-660.

4. Gaudino M, Benedetto U, Fremes S, Biondi-Zoccai G, Sedrakyan A, et al. (2018) Radial-artery or saphenous-vein grafts in coronary-artery bypass surgery. N Engl J Med 378(22): 2069-2077.

5. Aldea GS, Bakaeen FG, Pal J, Fremes S, Head SJ, et al. (2016) The Society of Thoracic Surgeons Clinical Practice Guidelines on Arterial Conduits for Coronary Artery Bypass Grafting. Ann Thorac Surg 101(2): 801-809.

6. Sousa-Uva M, Neumann FJ, Ahlsson A, Alfonso F, Banning AP, et al. (2019) 2018 ESC/EACTS Guidelines on myocardial revascularization. Eur J Cardiothorac Surg 40(2): 87-165.

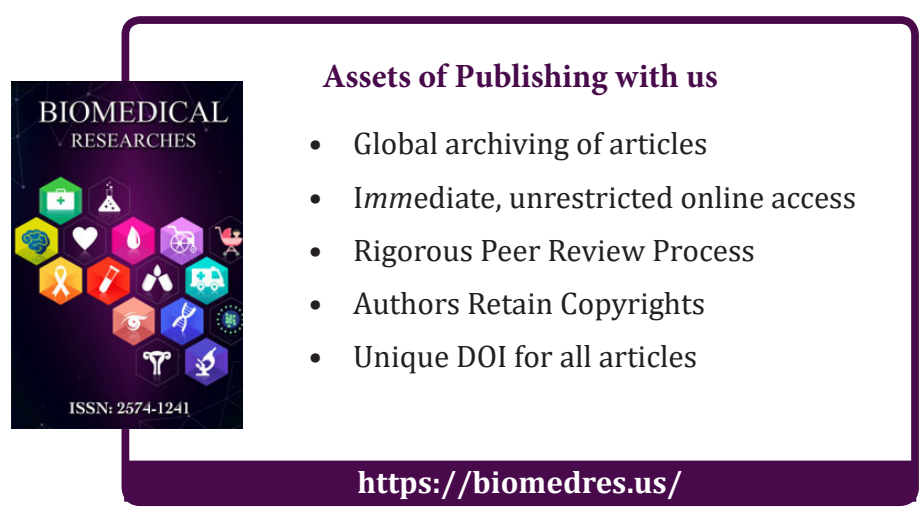

